\title{
The R\&D Research of Digital Content Platform
}

\author{
Analysis Based on numerical simulation \\ Fujin Zhang, Jie Shang, Bin Wang \\ Department of Public Economics \\ Xiamen University \\ Xiamen, China \\ E-mail:czzfj2006@163.com
}

\begin{abstract}
This paper studies the related problems which belong to research of digital content platform by using numerical simulation. Results from the research show that: under effect of network externality, the digital content platform with high-tech stock could only expand successfully when the network size beyond critical capacity. But, when the technological gap is big enough, the critical capacity could be 0 . Besides, we found the Nash equilibrium of $R \& D$ input is not necessary exist in the simulation without price, and the existence of equilibrium need special condition.
\end{abstract}

Keywords-R\&D; digital content platform; numerical simulation

\section{INTRODUCTION}

Technology R\&D is new breed, new technology, new service, and the research staff or R\&D institution use proper ways and means with certain material to meet the market demand. The digital content platform is different from normal digital content productions, the quality of normal digital content productions is depend on $R \& D$ input at this time, it doesn't have the natural inheritance of input and quality. But the R\&D of digital content platform has constancy, every period input would affect the final production quality and technical level, the provider of digital content platform needs continually input to fine down the older version and get newer or higher version production, and in this progress no or just a few users would switch.

Technical research of digital content platform decides its mode of expression and affects the value gained by the users. As the quality development of digital content platform, one side it needs depend on flexible application of existing digital technique, the other side it needs weeds bring forth new from the original knowledge ,and carry out research of new digital technique. Only continues improving the digital technique, the digital content platform could continue gets technical support and gains new means of expression, the creation of digital content could get richer, the users could get more value.

So the enterprises in free market would take the technical R\&D by themselves, and continues this process? Can outstanding technique defeat the poor one, achieve survival of the fittest and technical innovation, or have the possibility of subprime technology captures market? Is there having one optimal or balanced technical R\&D Input? All of these problems, we will discuss in the following and seek the answer through numerical simulation.

\section{MATHEMATiCAL MODEL}

\section{A. Description of Consumer Behavior}

Supposing that there have $N$ consumers on the market, there is a factor which can affect consumer decision defined as horizontal differentiation coefficient $h$ 。 Horizontal differentiation coefficient of Consumer is determined by (1).

$$
h_{i}=(i-1) /(N-1)
$$

And supposing that the consumer decision only affected by high-tech stock, network externality, horizontal differentiation coefficient, so the utility of consumer $i$ at the period $t$ is determined by (2).

$$
v_{i j, t}=k\left(1-\left|h_{i}-H_{j}\right|\right) T_{j, t} D_{j, t-1}^{\mu}
$$

In this formula, $H_{j}$ means the located position of $j$ th digital content platform in the horizontal differentiation coefficient space, which is fixed. $T_{j, t}$ means the technical stock of jth digital content platform at period t. $D_{j, t-1}$ means consumer scale of digital content platform $\mathrm{j}$ at $\mathrm{t}$-1period, which also is the original consumer scale of platform $j$ at $t$ period. $\mu$ is the factor of network externality when the consumer are making decision, $\mu$ is larger , the effect is more high.

In the R\&D process, the enterprises' input is continuous, so the technical stock $T_{j, t}$ of digital content platform is determined by (3)

$$
T_{j, t}=T_{j, t-1}+R_{j, t}^{\rho}
$$

In this formula, $R_{j, t}$ is the technical $R \& D$ Input of digital content platform j at period t. $\rho$ is transforming factor from input to technical stock, when $\rho$ is above 1,the marginal output of technical stock increases progressively. When $\rho=1$, there exists linear correlation between technical R\&D and technical stock, and when $\rho<1$, that means the marginal output decrease from the technical $R \& D$ to technical stock .

There must exist new technical followers with certain probability $\alpha$ in consumers. Compared to the intelligent 
consumers who have taken adaptive expectations, new technical followers don't treat the present scale of newer or older technique as the basis of utility evaluation. They keep an eye on the market, and optimistically think the market would be survival of the fittest. As the time past, the new technique would defeat the older one, and occupy all the market. So they are willing to be forerunner. For the new technical followers, whatever the how big the network size is, new technique is the best choice forever.

\section{B. Description of Enterprise's Behavior}

The market is oligopoly market composed by two enterprises which provide digital content platform, and the location $H_{j}(j=1,2)$ in the level difference coefficient, the original technical stock and consumers' network size are fixed. The enterprises decide the technical R\&D funds to optimize the utility at each period. Though the enterprise could obtain income through many ways, for the need of simplification, we suppose the income of enterprises depend on the market share. So we can set the profit of digital content platform $j$ at $t$ period as in

$$
\pi_{j, t}=a D_{j, t}-(1-s) R_{j, t}
$$

The profit of enterprise at $t$ period is actually in proportion to consumers' network size at period t, $a$ means transformation ratio(In this study, we set $a$ of two platforms is the same). $s$ means the subsidy applied by the government to assist the R\&D, when $s=0$,the enterprises undertake the all cost.

The enterprise $\mathrm{j}$ decides technical $\mathrm{R} \& \mathrm{D}$ input at each period based on maximum profit at period $\mathrm{k}$ by (5).

$$
\operatorname{Max} \sum_{t=k}^{k+n-1} \lambda^{t-k} \pi_{j, t}
$$

Where $\lambda$ is discount rate, $\lambda$ is determined by the enterprise's attitude to present and long term profit. In this study, we suppose $\lambda$ is fixed.

When $n=1$, the enterprise $\mathrm{j}$ is very nearsightedness, it only consider to obtain the biggest profit at $\mathrm{k}$ period. When $n \geq 2$, the enterprise $\mathrm{j}$ is foresight, who not only consider the profit at period $k+1$, but also consider the profit at period $k+n-1$.

\section{ANALYSIS BASED ON NUMERICAL SIMULATION}

\section{A. The Diffusion Path of New Technology Based on Network Externality}

Set $N=1001, \alpha=0$, and create a consumer group. Set $T_{1}=10, T_{2}=20$, and they are fixed. The original consumer scale of Platform 1 is $D_{1,0}=900$, and the original consumer scale of platform 2 change from 0 to 40 . The consumer group make the iteration themselves from period 1 to 6 , the market scale of platform 2 as in figure 1.

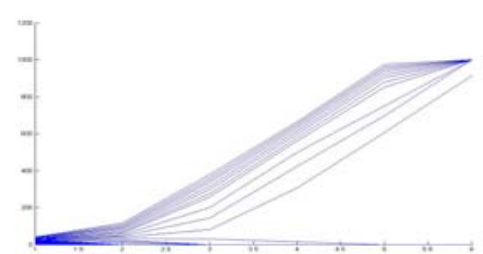

Figure 1. The diffusion path of platform 2

Figure 1 show that when the $D_{2,0}$ of platform 2 is very low, the market scale gradually reduced until no more consumer choose the platform 2.When the original consumer scale is high, the market scale gradually increased until occupy all the market. Though platform 2 has a higher technical stock than platform 1 , and the original net scale of platform 2 is larger than platform 1 , the final result of market competition is not necessary survival of the fittest affected by the network externality. If the installation foundation of the excellent technology is not enough, subprime technology would capture market.

Further, we select seven lines when $D_{2,0}=27,28,29$,

30, 31, 32, 33 in Figure 1, and put them into Figure 2.

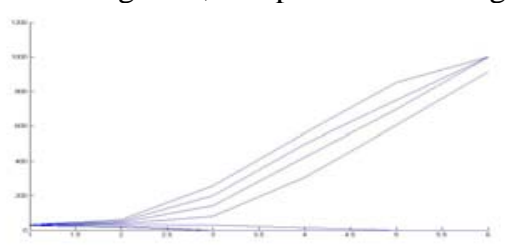

Figure 2. The diffusion path of platform 2 when $D_{2,0}$ $=27,28,29,30,33,32,33$.

According Figure 2, When $D_{2,0}<30$, the platform 2 goes downhill. When $D_{2,0} \geq 30$, platform 2 finally owns the market, achieving survival of the fittest. The little gap of original consumer scale would make different results; this is fit with the critical capacity in economics. For the random consumer group used in Figure 2, when the original network scale of platform 1 which delegate the old technique is 900 , the critical capacity is 30 .

The value of critical capacity is not fixed, different consumer characteristic, different technical stock and others which would affect the value of critical capacity. The critical capacity is not always above 0 . for example, setting $\alpha=0.05$, new technical followers would appear at a rate of $5 \%$. We simulated again, changing $D_{2,0}$ from 0 to 40 , and the consumers make iteration by themselves from period 1 to 5, so the market size of platform 2 is shown as Figure 3.

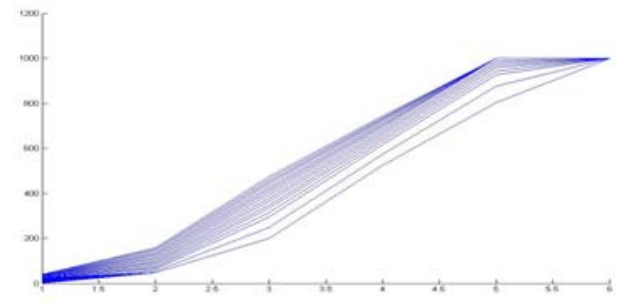

Figure 3.The market size of platform 2 when $\alpha=0.05$ 
According to Figure 3, when there are 5\% new technology followers in the market, the critical capacity of platform 2 to achieve market expansion is 0 . This means with the appearance of new technologies, the older one would lose of market and fall finally. There is no difficulty to expand for new technology. But this automatic survival of the fittest depends on the technological gap. When $T_{1}=10$ and $T_{2}=15$, the market size occupied by Platform 2 as shown in Figure 4.

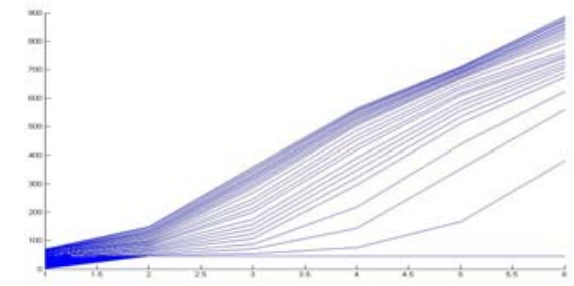

Figure 4. The diffusion path of platform 2 when $\alpha=0.05, T_{1}=10$

$$
T_{2}=15
$$

According to Figure 4, when the technology gap between the two platforms is becoming smaller, the result of market competition is not necessarily deciding the survival of fittest. The new technique could expand or not is decided by whose original network size beyond critical capacity or not.

\section{B. Nash-equilibrium Existence Analysis in Duopoly Market}

When $N=1001$, $\alpha=0.05$, we obtain a random consumer group. Setting $H_{1}=0.25, H_{2}=0.75$,technology stock of both digital content platforms are $T_{1,0}=10$ and $T_{2,0}=15$ respectively. Original consumer scale of two platform are $D_{1,0}=900$ and $D_{2,0}=10$. Transformation ratio of consumer network size to profit is 0.2 and discount rate of profit is 0.95. Other parameters are set as follows: $\rho=0.5, s=0$, $n=5$.

R\&D input of Platform 1 is changed from 0 to 100 , and we set step length as 10 .With different value of $R_{1,1}$, The platform 2 optimize its profit to decide R\&D input. Under different $R_{1,1}$ the best technical $\mathrm{R} \& \mathrm{D}$ input curves are shown in Figure 5 marked with "o".

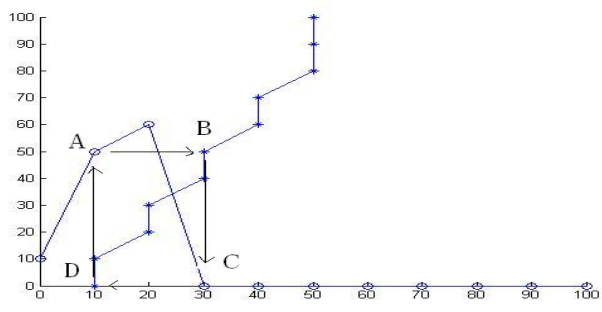

Figure 5. Nash-equilibrium Existence Analysis

According to Figure 5, the curve "o" shows that when the old digital content platform with low technology stock has the more users, the quantity of R\&D input of new digital content platform is affected by the competitor's level. When the platform 1 has a low investment level, the platform 2 is willing to carry out the technical R\&D input. But when the input of platform1 equal to or above 30,the platform 2 lose its $R \& D$ incentive.

Using the same way, we could get the optimal reaction curve of platform 1 corresponding to platform 2, which is marked with “*” in Figure 5."*” curve means the optimal reaction curve of platform 1 under the input level of different platform 2.

According to the Figure 5, when both of the two enterprises make $\{0,10,20,30,40,50,60,70$, $80,90,100\}$ as strategy space of technical R\&D input, the pure strategy Nash equilibrium is not existed. (In Figure 5,there doesn't have the concurrent point of "o" curve and "*” curve ) 。 This means the pure combined strategy of R\&D which could make both of two enterprises be satisfied does not exist: at current situation, given the input of rival, my input is optimal.

Supposing that both of the enterprises could observe strategy of each other's rival in very short time, and make action. In this way, whatever begins from which combined strategy, the strategy of the two enterprise would finally circle among $\mathrm{A}(10,50) ; \mathrm{B}(30,50) ; \mathrm{C}(30,0)$ and $\mathrm{D}(10,0)$ till the situation of market change, which is shown in Figure 5.

From the analysis above, the original network scale of platform $2 D_{2,0}=10$ is very small. But we want to know when the original scale of platform 2 is gradually improved, what will happen to the two optimal reaction curves and Nash equilibrium. So we keep all kinds of parameter and random consumer group, and change original network scale of platform 2 from 10 to 100 gradually.

According to the results, the improvement of original network scale at platform 2 makes a obvious effect to the optimal reaction curve of $R \& D$.

The effect made by improved platform2 size shows its importance. We don't discuss with the sensibility of curve to scale. We pay more attention to the possibility of Nash equilibrium existence, but we did not find the pure policy Nash equilibrium in simulation. One possible cause is our limit of policy space. In simulation above, we suppose that the $R \& D$ input change as a multiple of 10 . From the Figure 5, we could get the pure policy Nash equilibrium though changing the step length. To analyze the Nash equilibrium in more big policy space, we change the step length from 10 to 2 , the policy space of two enterprises are expanded to $\{0$, $2,4,6,8,10,12,14,16,18 \cdots \cdots 96,98,100\}$. Remain the other parameters and random consumer group unchanged, and get the optimal reaction curve shown in figure 6.

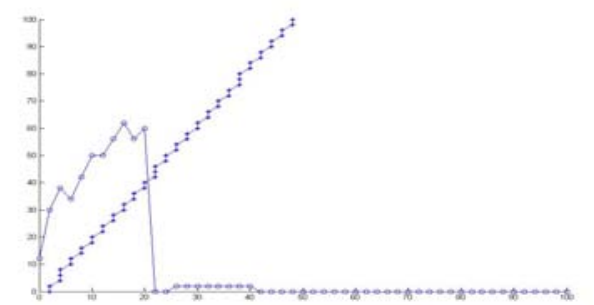

Figure 6. Nash-equilibrium Existence Analysis(step length=2) 
According to figure 6, although we lessen the step length and the strategy space is expended, Nash equilibrium barely exists in our simulation. The Nash equilibrium must not exist in the market which is no price as lubrication, and influenced by network externality. Through our study, we also found that the Nash equilibrium can exist in a particular situation.

\section{CONCLUSION}

This paper studies the related problems which belong to research of digital content platform by using numerical simulation. Results from the research show that: under effect of network externality, the digital content platform with high-tech stock could only expand successfully when the network size beyond critical capacity. But, when the technological gap is big enough, the critical capacity could be 0 . Besides, we found the Nash equilibrium of R\&D input is not necessary exist in the simulation without price, and the existence of equilibrium need special condition.

\section{ACKNOWLEDGMENT}

Fujian province soft project (2012R0082) is sponsor.

\section{REFERENCES}

[1] Falvey. R., Foster.N. and Greenaway.D.”Intellectual Property Rights and Economic Growth". Review of Development Economics, 2006,10,(4):700-719.

[2] Yong Gyu Joo, So Young Sohn.”Structural equation model for effective CRM of digital content industry". Expert Systems with Applications,2008,(34):63-71.

[3] Paula M C Swatman,Cornelia Krueger, Kornelia van der Beek.”The changing digital content landscape: An evaluation of e-business model development in European online news and music”. Internet Research,2006:53-80.

[4] Cristina Mussinelli. "Digital Generation: Overview of Cultural and Entertainment Content Usage in Italy”. Pub Res Q,2009,(25):94-100.

[5] D.O. Choi and J.E. Oh ."Efficiency Analysis of the Digital Content Industry in Korea: An Application of Order-m Frontier Model”. Productivity, Efficiency, and Economic Growth in the Asia-Pacific Region,2009:299-314.

[6] Luca Lambertini,Raimondello Orsini."Process and product innovation in a vertically differentiated monopoly". Economics Letters, 2000,(68):333-337.

[7] Pio Baake,Anette Boom.”Vertical product differentiation,network externalities,and compatibility decision". International Journal of Industrial Organization,2001,(19):267-284.

[8] Bing Jing."Network externalities and market segmentation in a monopoly”. Economics Letters, 2007,(95):7-13

[9] Banerjee, D. S.Lobbying and Commercial Software Piracy. European Journal of Political Economy, 2006,22,(1):139-155.

[10] Michael Wolf, Clint Wheelock. "Digital content unleashed”. Journal of Digital Asset Management, 2007,3(5):247-258. 